\title{
Solutions for increasing the quality of hydro-technical building elements obtained by numerical simulation
}

\author{
Alexandru Fodorean ${ }^{1}$, Adrian $\mathrm{Cureu}^{1}$, Oana Giurgiu ${ }^{1}$, and Dan Opruța ${ }^{1}$ \\ ${ }^{1}$ Techincal University of Cluj-Napoca, Department of Mechanical Engineering, Cluj-Napoca, Romania.
}

\begin{abstract}
Sewage treatment remains a delicate subject and requires technical improvements to increase the efficiency of the systems responsible for the treatment. Numerical simulations are also a very useful tool, especially if they are used during the design phase. Thus, the paper aims to present the results obtained by CFD numerical simulations in the case of an important element within an existing wastewater treatment plant, namely the waste water treatment well, thus obtaining constructive solutions of a better functionally to the designed version. Through these, the work demonstrates the necessity of analyzes with CFD methods during design of the main elements of hydrotechnical constructions, but also the necessity of adjusting the numerical models with results obtained from experiments, measurements. The results show that the modifications described in the paper would bring significant improvements in waste disposal.
\end{abstract}

\section{Introduction}

For better water management, it is necessary the use of simulation software tools from the design phase, thus optimizing the elements of the hydrotechnical constructions. These elements in order to be able to perform the functions in the best conditions must be analyzed in several constructive configurations, which is extremely easy when using mathematical models that can be solved by numerical methods. Mathematical models, in turn, have to be adapted to the real situation as much as possible, so comparisons with real situations or with results obtained on experimental stands at a smaller scale must be made. Following the experiments on a real model or on site, the numerical models are adjusted to become a universal tool needed by design engineers. $[1,2]$

The presence of the sand and mud mixture in sewers and wells can cause a loss of hydraulic capacity that leads to operational problems such as surcharging surface flooding and premature operation of overflows with a consequent increase in the pollution watercourses. [3]

Waste water treatment is a group of physical, chemical, biological and bacteriological operations, which decrease the loading of organic and inorganic pollutants and bacteria, to protect the nature. According to the technologies and the instruments used, it results clean water in different level of decontamination. [4]

Existing assessment methods, for water treatment plants, consider the factors such as the efficiency of the installation, the amount of water entering and the percentage of demand that is mitigated and often wrongly represent the current position of the water treatment plant due to the equal consideration settled for all the parameters. The deflection remarked in the existing assessment methods can be assigned to the subjective decision and not considering the influence of parameters on the output from the plant. [4]

Iliescu et al [5] also focused on self-cleansing conditions which have to be satisfied in order to ensure the good exploitation of sewage system. They specified that the minimum velocity $0.7 \mathrm{~ms}^{-1}$ have to be ensured in order to maintain sewage self-cleansing, no matter the pipe diameter and material.

This paper presents a numerical simulation study that was conducted on the dewatering stream through the deck and the pumping probe from the waste water treatment plant at the primary stage where the pollutant removal processes are carried out on large particles and solid particles in suspension or sedimentation.

The concern of this study is that the wastewater flow through the well and the pumping probe at the treatment plant is to eliminate the deposition of solid particles into the well, by studying the different geometric shapes that the well can have

Due to the continuous running of the water treatment system, the reliability is necessary to be studied starting from the designing stage. This is a pre-condition to provide water decontamination according to the water quality standards. [6]

Another purpose of the paper is to present the fact that by the use of simulation tools for the design of this types of constructions, leads practically to better water management throughout the operation life of the hydrotechnical system.

It is known from literature that the erosion of sediments could be parametrized by critical shear stress. As referred in [7] no sooner does the bed shear stress reach a certain critical value, then the sediments budges.

* Corresponding author: dan.opruta@termo.utcluj.ro 
A prerequisite condition to determine the bed shear stress is that of assessing the flow velocity field in the whole well, particularly near its walls of the well.

The main purpose of the present paper is that of assessing the velocities and shear stress distributions by numerical simulation in order to improve self cleaning conditions for the pump well. Three cases will be studied in this paper, one corresponding to the actual well and the others two are suggested as probable solutions for the improvement of the well.

\section{Case study}

The Târgu Lăpuş Treatment Plant is located in Târgu Lăpuş, in the river area, Târgu Lăpuş River. It was realized in 1975 and was designed for a capacity of purge rate of $91 / \mathrm{s}$ with an $82 \%$ yield for CBO5 and $74 \%$ for suspensions. The new Wastewater Treatment Plant is projected with a capacity of purge at more than a double of the initial purge rate capacity (19 1/s) [6].

The most important steps in a waste water treatment are water transport, homogenous flow and constant flow.

Waste water comes out from the grills basin and get in the pumping well through two $400 \mathrm{~mm}$ diameter pipes and is evacuated by two submersible pumps connected to 3" diameter pipes in the desander and the fat separator. (Figure 1; 2 and 3) [6]. Reynolds number of the flow through the inlet ducts is 19000 .

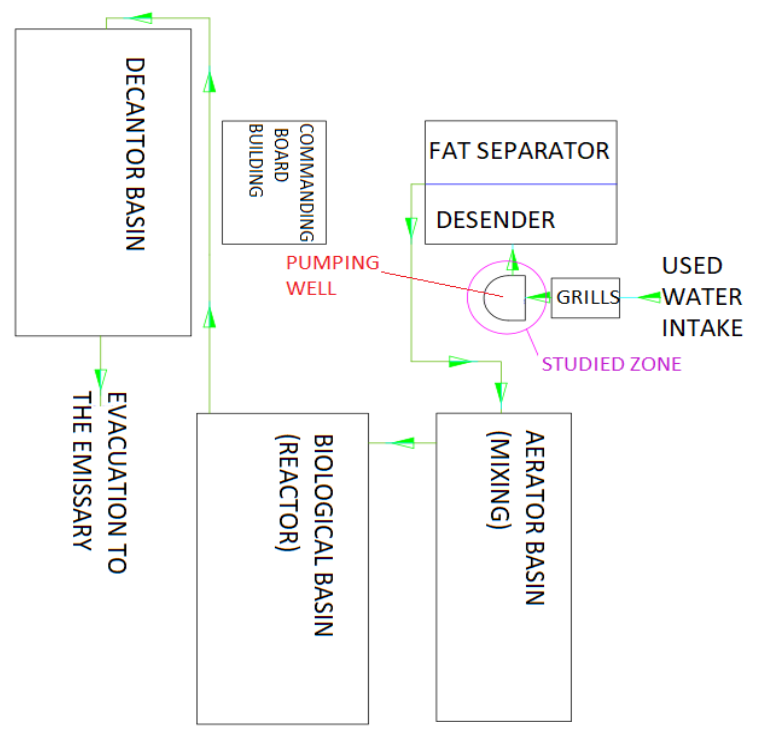

Fig.1. Plan of the wastewater treatment plant.

The investigated zone of the wastewater treatment plant is in the wastewater extraction zone, the well, where it unfolds the primary treatment of the plant in order to obtain an effluent that complies with the evacuation conditions imposed by the regulations in vigor. [6]

The studied problem of the case consists in depositing of residual materials on the bottom of the well, especially at the right-angle intersection of the walls with the bottom of the well. Those deposits are due to the smaller sand grains that are characterized by sharper corners and edges which enforce greater resistance to wastewater flow. Because of this high angularity are imposed/implicated high internal friction angles, so the grains can support a higher traction force [3].

In presented case study, Târgu Lăpuş Treatment Plant meteo conditions are a decisional factor that influence the quantity of sand and mud mixtures that slows the waste water flow through the well and increase the deposits of it on the bottom.

Due to this depositing of residual materials, at a certain level of deposits, the pumps that extract the wastewater are blocked with residual materials weekly [6]. This common for wastewater treatment plants [8].

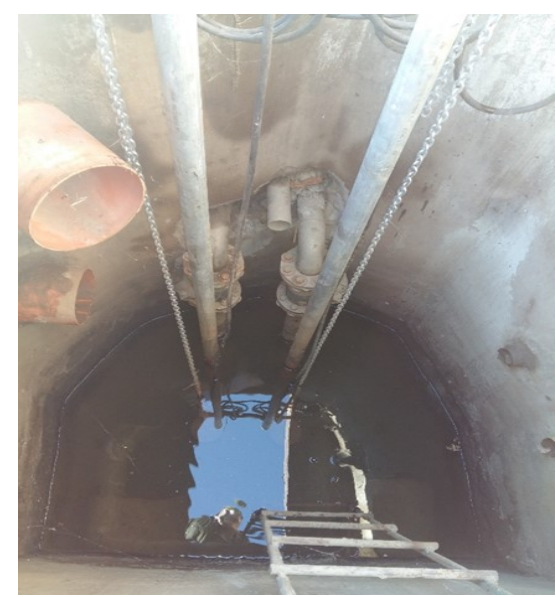

Fig. 2. The well for the pumping station (studied zone) [2].

\section{Simulation model and method}

For this case, the method used is Computational Fluid Dynamics (CFD) by the use of Ansys software. The chosen turbulence model for the studied case is SST k- $\omega$ (Menter's Shear Stress Transport) turbulence model that is widely used, with two equations. The model used model it's a blend between $\mathrm{k}-\omega$ and $\mathrm{k}-\varepsilon$ turbulence model. The $\mathrm{k}-\omega$ model is used for inside area of the boundary layer and it's changing to k- $\varepsilon$ in the freestream. The SST k - $\omega$ turbulence model model was developed in 1994 by F.R. Menter to study the freestream hard sensibility of the $\mathrm{k}-\omega$ and also to improve the anticipation of adverse pressure gradients. The SST k- $\omega$ model is based on physical experiments and tests trying to look for possible solutions for typical engineering cases. [9]

The model of the studied geometry is presented in Figure 3, and the affected areas in Figure 4.

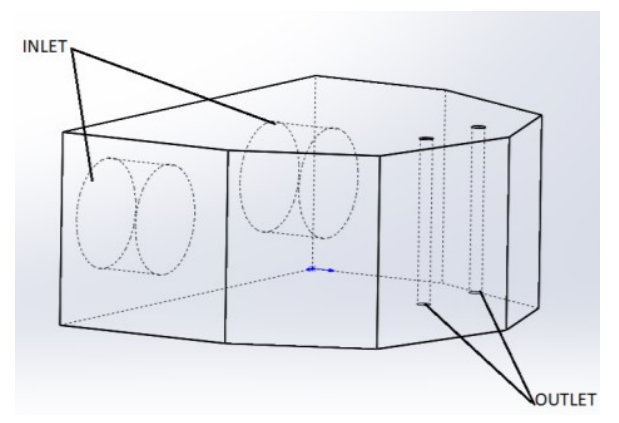

Fig. 3. Actual geometry of the well. 


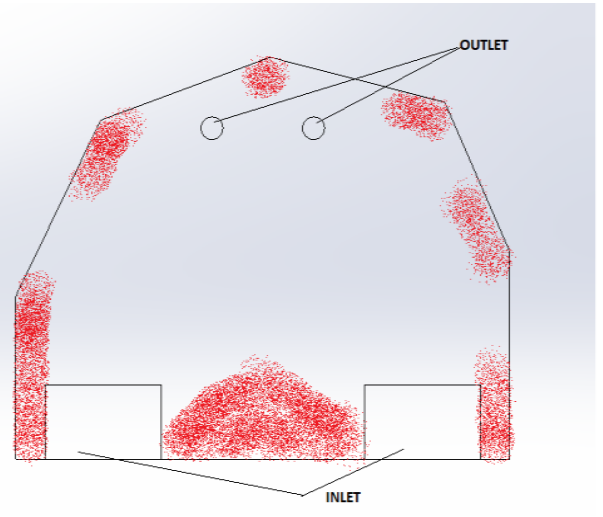

Fig. 4. Affected areas as described by the beneficiary.

Wall shear stress is an important parameter when studying material deposition on the bottom of the waste water treatment well or sewage pipes $[10,11]$.

An important influence in deposition of residual materials is geometry of the well, more accurate the right-angle intersection between the wall and the bottom of the well. To resolve the problem of residual material depositing in the initial geometry, the solution is to modify the geometry of the well. Hence two cases are proposed:

- Well with inclined base;

- Well with rounded base.

\subsection{Case 1 - Well with inclined base}

The reason of choosing this solution is to increase the wall shear stress on the bottom of the well, so the deposits should be less than if the bottom is plane

Inclination angle of the bottom will increase the velocity on the bottom of the well which will lead to an increase in the shear stress between particles of sand and mud mixture and the velocity of the waste water flow.

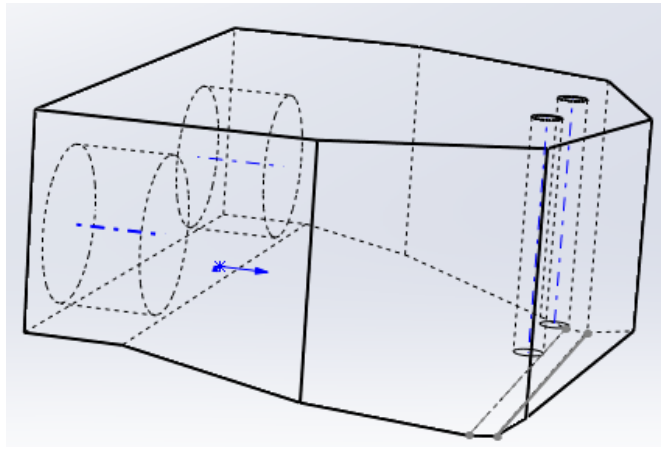

Fig.4. Case 1 - Well with inclined base.

\subsection{Case 2 - Well with rounded base}

The reason of choose this solution is to increase the wall shear stress at the right-angle intersection between the bottom and walls of the well, so the deposits should be less than if the intersection between the bottom and the walls is a right angle.

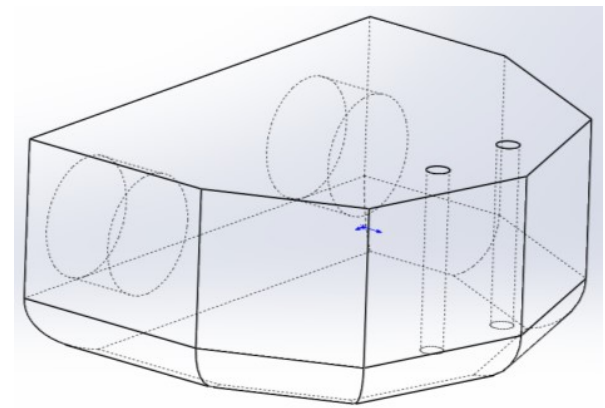

Fig.5. Case 2 - Well with rounded base.

For complex geometries, when nodes are irregularly distributed the near wall modeling of the flow, for SST $\mathrm{k}-\omega$ based model is resolved down to the viscous sublayer. [9]

In Figures 6, 7 and 8 is presented the numerical grid of each studied geometry by section view showing the boundary layer. The number of the elements for each case was: $475 \mathrm{k}$ elements for actual case, $480 \mathrm{k}$ elements for first and second geometry solutions.

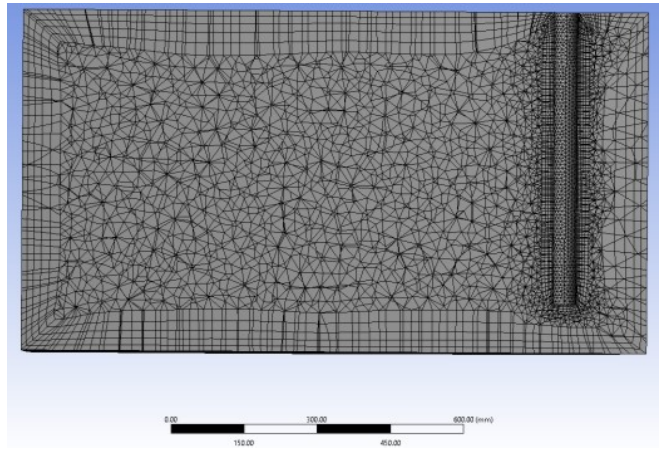

Fig. 6. Numerical grid for the actual case.

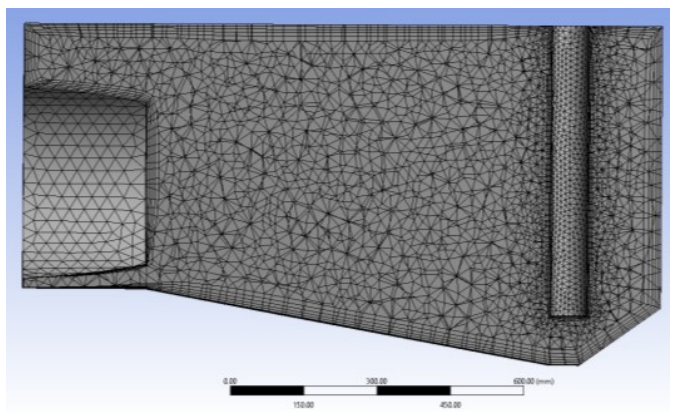

Fig. 7. Numerical grid for case 1.

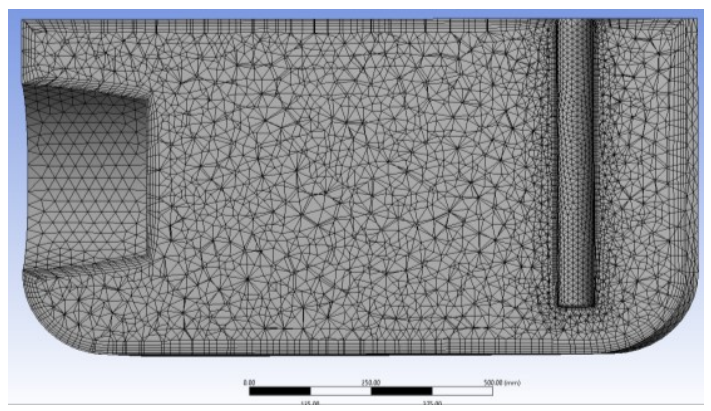

Fig. 8. Numerical grid for case 2. 


\section{Results and discussions}

Geometry favors the wall shear stress on the bottom of the well by the inclined surfaces increasing the value of this force, decreasing the residual materials deposited on the bottom of the well.

In Figures 9, 10 and 11 is shown the wall shear stress contours values on the bottom of initial case geometry, case 1 geometry and case 2 geometry.

Reading the results from the color map scale the values are situated between 0 and $0.17 \mathrm{~Pa}$.

Large values for the wall shear stress means it will be less chances for the deposits of residuals. The maximum value reached on the color map scale is $0.17 \mathrm{~Pa}$ in the case of the "Case 2 geometry", well with rounded base.

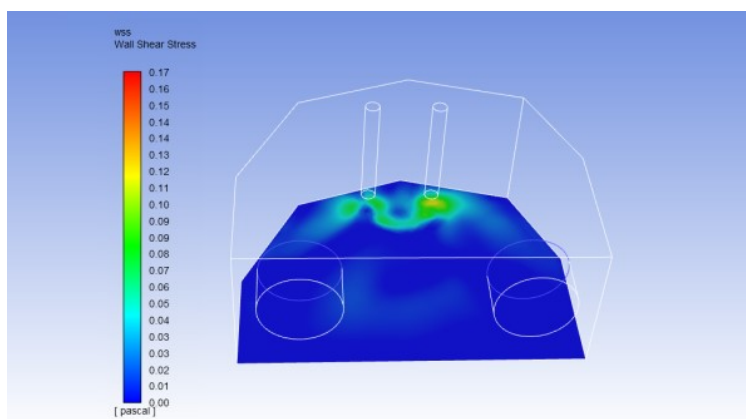

Fig. 9. Wall Shear Stress for the bottom of the actual well geometry.

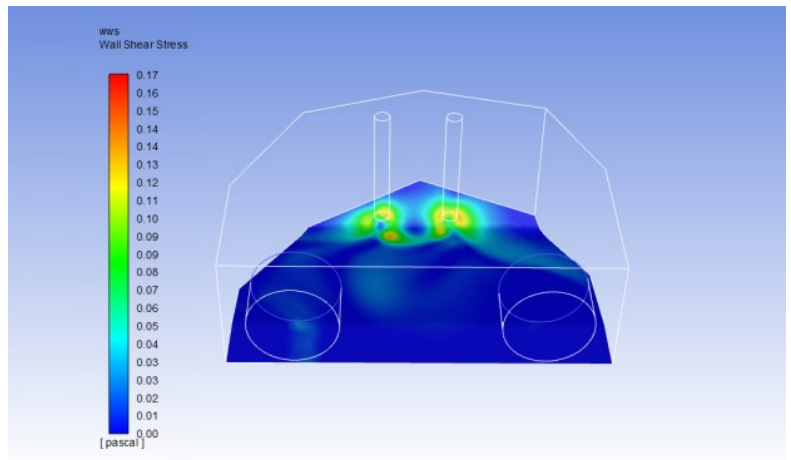

Fig, 10. Case 1 geometry-Bottom Wall Shear Stress.

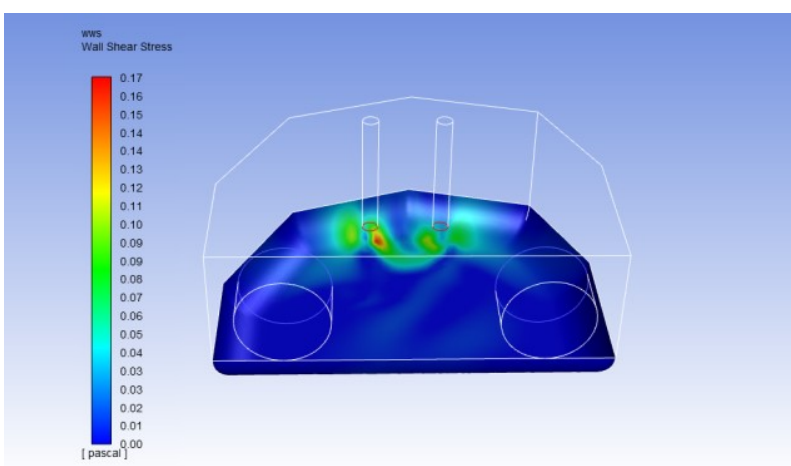

Fig. 11. Case 2 geometry- Bottom Wall Shear Stress.

Verifying the area corresponding to this value is observed that geometry favors the waste water flow due to high wall shear stress existing in the affected zones compared with the actual case, particularly at the intersection between the walls and the bottom of the well, that are presented in Figure 4.

Using a rounded connection between the walls and the bottom (Figure 11) instead of the right angle of the actual geometry we can observe that the corners with the vertical wall presents higher values of wall shear stress which led to the idea that in this case the chances for mud and sand mixture deposition in the areas identified by the beneficiary (figure 4) are lower.

The minimum of the high values between the three different geometries is $0.12 \mathrm{~Pa}$ in actual case geometry that is unfavorable by the hypothesis.

The second of the highest values of the studies is $0.14 \mathrm{~Pa}$ in case of "Case 1 geometry", the well with inclined bottom. In this case, the favorable values on the color map scale is between 0.04 and $0.14 \mathrm{~Pa}$ on a high area of the well bottom comparative to the other geometries.

The "Case 1 geometry" is less favorable because we have large values for the wall shear stress in areas unaffected by sand and mud mixture deposition and very small values of wall shear stress in areas affected by this process (see Figure 4).

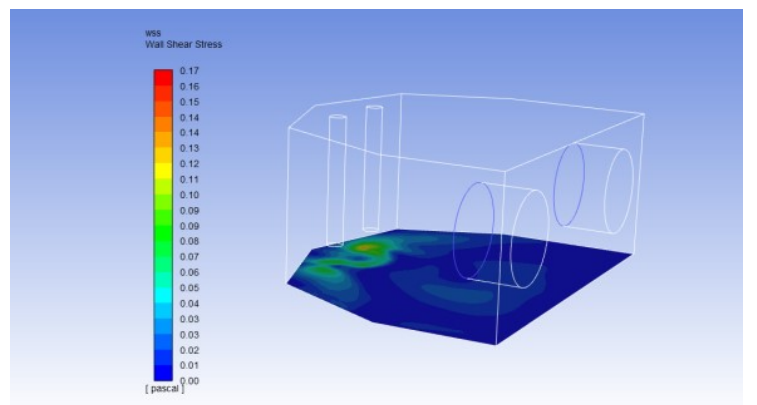

Fig. 12. Initial case geometry-Bottom Wall Shear Stress.

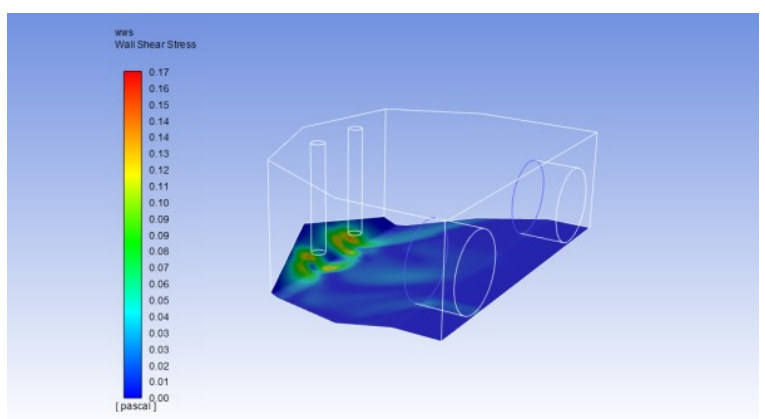

Fig. 13. Case 1 geometry-Bottom Wall Shear Stress.

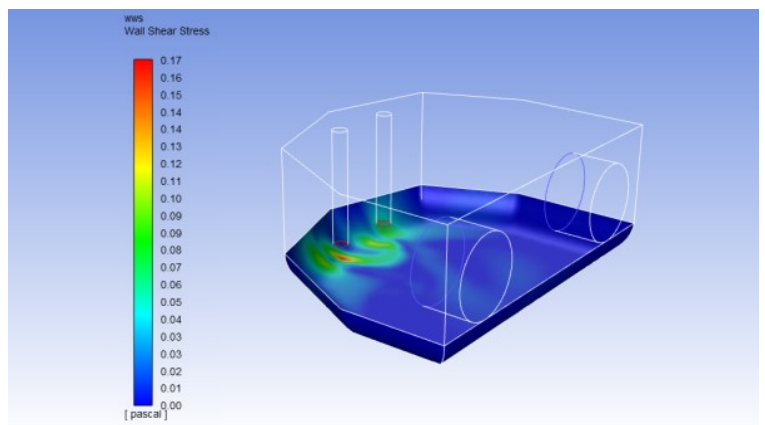

Fig. 14. Case 2 geometry- Bottom Wall Shear Stress. 
In Figures 12, 13 and 14 is shown the color map of the wall shear stress values on the bottom of initial geometry, case 1 geometry and case 2 geometry, side views.

The results shows that the two geometry adjustments described above would bring improvements in waste water disposal compared with the initial geometry.

Hence, using the numerical simulation, in the design of these elements can be of real help in order to obtain good overall qualitative results, simply modifying the geometry with the purpose of passive influence in the sand and mud mixture deposition. These simple shape changes that can bring significant improvements are reported in other hydraulics sub-domains also in: [1, 2 and 8$]$.

Figures 15, 16 and 17 shows vector fields for each studied geometry.

Analysing the vectors fields from the colour maps presented in above mentioned figures, it can be observed that in actual case (Figure 15), velocities at the bottom of the well are very low, this representing a disadvantage, favouring a possible deposition for the sand and mud mixture (Figure 4).

Figure 16, shows the "Case 1 geometry" field flow. We can observe that the bottom velocities are higher than in the actual case.

In Figure 17 we can observe the "Case 2 geometry" velocity field. The velocities are in the same range like for the "Case 1 geometry" but with higher values particularly behind the suction ducts which is between the affected zones presented in Figure 4.

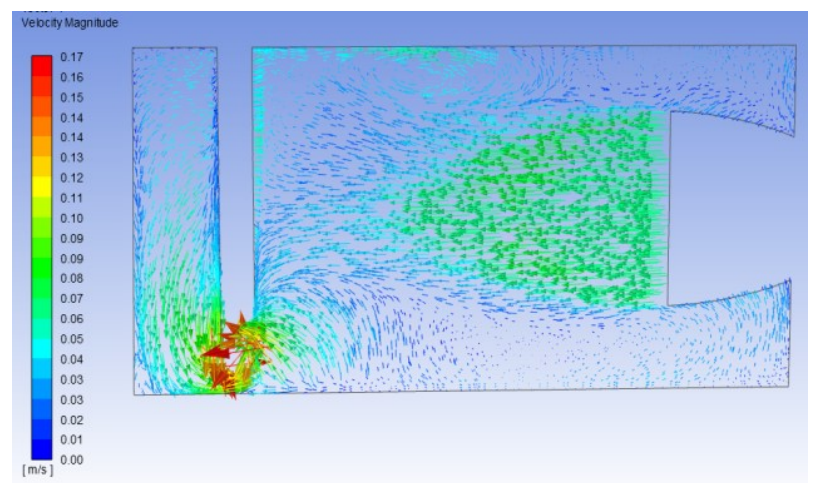

Fig. 15. Actual geometry-section plane of vectors field.

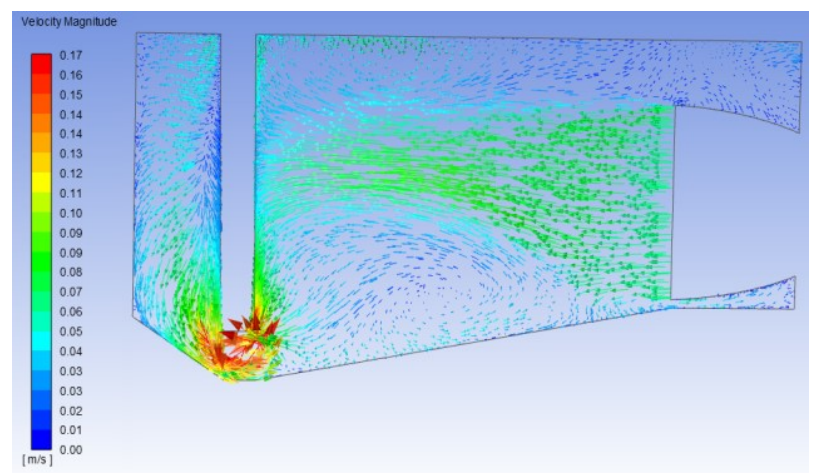

Fig. 16. Case 1-section plane of vectors field.

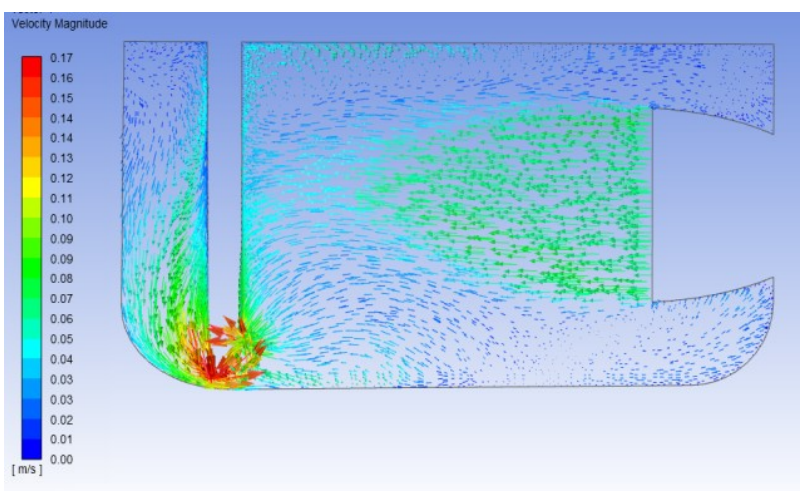

Fig. 17. Case 2-section plane of vector field.

\section{Conclusions}

This paper presents a CFD study for the case of an important element within an existing waste water treatment plant, waste water treatment well, thus obtaining constructive solutions of a better functionally for the designed version.

For this purpose, besides the actual case, two different geometries of the base of a waste water treatment well were analysed, one with inclined and one with rounded base.

According to the results, the higher values of wall shear stress in the areas affected by the deposition of sand and mud mixture (Figure 4) were obtained for the geometry with inclined base.

Further studies will be focus on a combined geometry between the two already proposed cases, using different values of base inclination angle.

\section{References}

1. D.V. Banyai, I.R. Pop, D. Opruta, L.I. Vaida, "Optimal flow control for increased electricity production in hydropower plants" I.C.P.R.Q.I.E.M., ISBN: 978-606-737-309-7, pp. 95-98, (2018)

2. I.L., Marcu, D.V. Banyai,"Analytical model of the connection pipes of the alternating flow driven hydraulic systems" Hidraulica Magazine of Hydraulics, Pneumatics, Tribology, Ecology, Sensorics, Mechatronics, No. 3, Pp. 80-85, ISSN 1453 - 7303, (2013)

3. I. Panagiotopoulos, G. Voulgaris, M.B. Collins "The influence of clay on the threshold of movement of fine sandy beds" Coastal Engineering, No. 32, Pp. 19-43, ISSN: 0378-3839 (1997)

4. E. Baruth, "Water Treatment Plant Design 4th edition" American Society of Civil Engineers, Reston, VA, McGraw-Hill, ISBN: 0-07-141872-5, pp. 896, (2004)

5. M. Iliescu, M. Sandu, I. Nastase, E. Iatan, F. Bode, "An experimental approach Regarding the Sewage Self - Cleansing Condition" Energy Procedia, No. 85, Pp. 266-272, ISSN: 1876-6102, (2016) 
6. A. Cureu, F Bode, "Study of the velocity of the flow in wastewater treatment plant" Proceedings of International Conference on Hydraulics and Pneumatics -HERVEX, ISSN 1454 -8003, Pp. 356$362,(2017)$

7. M.F. Ahmad, P. Dong, M. Mamat, W.B Wan Nik, "The Critical Shear Stresses for Sand and Mud Mixture" Applied Mathematical Sciences, Vol. 5, No. 2, Pp. 53-71, (2011)

8. D. Banyai, I. Sfarlea, D. Opruta, "Experimental research on variable hydraulic resistors of servohydraulic valves" I.C.P.R.-Q.I.E.M., UTPress ClujNapoca, ISBN: 978-606-737-180-3, (2016)

9. M Sandu, F Bode, P Danca, I Voicu, "Water flow structure optimization between the screenings and grit removals in a wastewater plant”, ENERGY and ENVIRONMENT (CIEM), 2017 International Conference on, 101-104

10. F. Bode, K. Sodjavi, A. Meslem, I. Nastase, "Numerical prediction of wall shear rate in impinging cross-shaped jet at moderate Reynolds number" Scientific Bulletin - University Politehnica of Bucharest, Series D: Mechanical Engineering, No. 76, Pp. 256-258, ISSN 1454-2358, (2014)

11. E Iatan, M Iliescu, F Bode, I Nastase, RM Damian, M Sandu "Numerical study for open-channel flow over rows of hemispheres" Energy Procedia 85, 260-265, 2016

12. M Iliescu, M Sandu, I Nastase, F Bode, E Iatan "Study of free surface flow in sewage pipes" International Multidisciplinary Scientific GeoConference: SGEM: Surveying Geology \& mining Ecology Management, 2016 